\title{
Effects of Hybridization of Carbon and Polypropylene Short Fibers as Reinforcement on Flexural Properties of Fine Aggregate Concretes
}

\author{
Mana Halvaei ${ }^{a}$, Masoud Jamshidi ${ }^{b^{*}}$, Masoud Latifi ${ }^{\mathrm{c}}$ \\ ${ }^{a}$ Textile Engineering Department, Amirkabir University of Technology, Tehran, Iran. \\ ${ }^{b}$ Polymer research lab, Chemical Engineering Department, Iran University of Science and Technology (IUST), Tehran, Iran. \\ ${ }^{c}$ Textile Engineering Department,Textile Excellence \& Research Centers, Amirkabir University of Technology, Tehran, Iran
}

Received 26 August 2016; Accepted 23 October 2016

\begin{abstract}
Nowadays, the advantages of short fibers as reinforcement in cement based materials are well known. In this paper, the effect of hybridization of short polypropylene (PP) and carbon fibers on flexural properties of a fine aggregate concrete has been investigated. Samples with dimensions of $230 \times 100 \times 9 \mathrm{~mm}$ containing $2 \mathrm{vol} \%$ of the polypropylene and carbon fibers with 6 and $8 \mathrm{~mm}$ length were made. The PP to carbon fiber proportion in the samples were selected as $100: 0,75: 25,50: 50,25: 75$ and 0:100. A four-point bending test was carried out on all the samples to investigate the flexural behaviour. It was found that the addition of carbon fibers significantly increases the flexural load (i.e. 260\%). The application of PP fibers leads to a $2590 \%$ increase in the toughness compared to the control sample. It was also found that the sample with carbon to PP ratio of 75/25 shows the optimum results and it leads to 190\% and $2070 \%$ increment in the flexural load and toughness, respectively, in comparison to the control sample.
\end{abstract}

Keywords: Fine Aggregate Concrete; Flexural Properties; Carbon Fibers; Polypropylene Fibers; Strain Hardening Behavior.

\section{Introduction}

Cement materials are brittle in nature and their flexural and tensile strengths are much lower than their compressive strength. Utilization of short staple fibers is one of the effective methods to overcome this weakness [1-3]. Usually, the addition of fibers into the matrix improves flexural strength, energy absorbent capacity, ductility and toughness of the composite $[4,5]$.

The effect of utilizing a variety of fibers such as steel fibers [1], glass fibers [6], carbon fibers [7], synthetic fibers $[2,8]$ and natural fibers have been investigated. Fibers with high strength/modulus lead to an increase in composite strength, while low modulus fibers increase the ductility of the composite. The use of hybrid fibers has also been considered in order to achieve both high strength and ductility [9].

Carbon fibers are high strength/modulus fibers which are alkali resistant [10]. Therefore, they have been used as reinforcement in cement based composites. The addition of carbon fibers leads to significant improvement in flexural strength of cement paste and concrete. Both the tensile and flexural strengths of the cementitious materials increase with an increase in the fibers length and content [11-13]. For example, the addition of $0.6 \mathrm{vol} \%$ of carbon fibers $30 \mathrm{~mm}$ in length has increased the concrete flexural strength and ductility by $20 \%$ and $50 \%$, respectively [14].

Generally, carbon fiber reinforced concretes show good tensile and flexural properties, low dry shrinkage, high specific heat, low thermal conductivity, high electrical conductivity and high abrasion resistance [15]. However, the usage of these fibers leads to an increase in the composite cost.

\footnotetext{
*Corresponding author: mjamshidi@iust.ac.ir
} 
Polypropylene fiber is a kind of polymeric fiber with low strength/modulus and high elongation. The effect of the PP fibers length and content on the physical and mechanical properties of the concrete has already been investigated. The utilization of $0.35 \mathrm{vol} \%$ of PP fibers $12 \mathrm{~mm}$ in length has improved the flexural strength of the concrete by $30 \%$ [16].

In the case of hybrid systems, steel fibers with high strength/modulus are usually used with a kind of synthetic fiber. Yao et al. [17] studied the compressive, tensile and flexural behavior of three types of hybrid composites containing carbon-PP, carbon-steel and steel-PP fibers with 0.5 volume percentage. The maximum strength and ductility have been obtained using the carbon-steel fiber reinforced sample. This is due to the same modulus and synergistic interaction between two reinforcement fibers.

Song et al. [18] also investigated the effect of the combination of the carbon and steel fibers on compressive and impact properties of the concrete. It was found that the hybridization of these two fibers could enhance the concrete performance in macro crack bridging and micro crack delaying.

The hybridization of the PP and steel fibers at different content and ratio has been used as well. The best flexural, tensile and compressive behavior has been achieved using the sample with a steel/PP ratio of 75:25 [19-21]. The compressive strength, flexural strength and deflection of the sample containing $1 \mathrm{vol} \%$ steel/carbon fibers with a ratio of 75:25 have been increased to $18 \%, 80 \%$ and $84 \%$, respectively in accordance with the control sample [19].

It is obvious that although the hybridization of fibers has been widely investigated, the combination of carbon and polypropylene fibers has not been exactly considered. It should also be noted that the researchers usually focus on the properties of cement paste, mortar or ordinary concrete. This is while the properties of the matrix could have a significant effect on the interfacial interaction between the fibers and matrix.

Engineered cementitious composite (ECC) is a new type of fiber reinforced concrete. Coarse aggregates have been removed from the mix design and it contains 2 volume percentages of fibers. ECC shows multiple cracking and thus strain hardening behavior during loading [22, 23].

Although the effects of utilizing a variety of natural and synthetic fibers have been investigated on the mechanical properties of the ECC, no report has been observed regarding the usage of the carbon fibers in this material. Therefore, in this paper, carbon fibers (as primary reinforcement) and polypropylene fibers (as secondary reinforcement and cost regulator) were used in the ECC mix design. The effects of fibers on flexural behavior of the composite in single and hybrid usage form were investigated.

\section{Experimental}

\subsection{Materials and Methods}

Portland cement type I, manufactured by Tehran Cement Company was used in this study. Fine aggregate silica sand with sand to binder ratio of 0.36 and the maximum grain size of $210 \mu \mathrm{m}$ was used to maintain adequate stiffness and volume stability of the matrix. In order to obtain self-consolidating fresh properties of the matrix, the aggregate particle size of the components of the mix design should be properly graded [24]. Figure 1. shows the particle size distribution of the used silica sands.

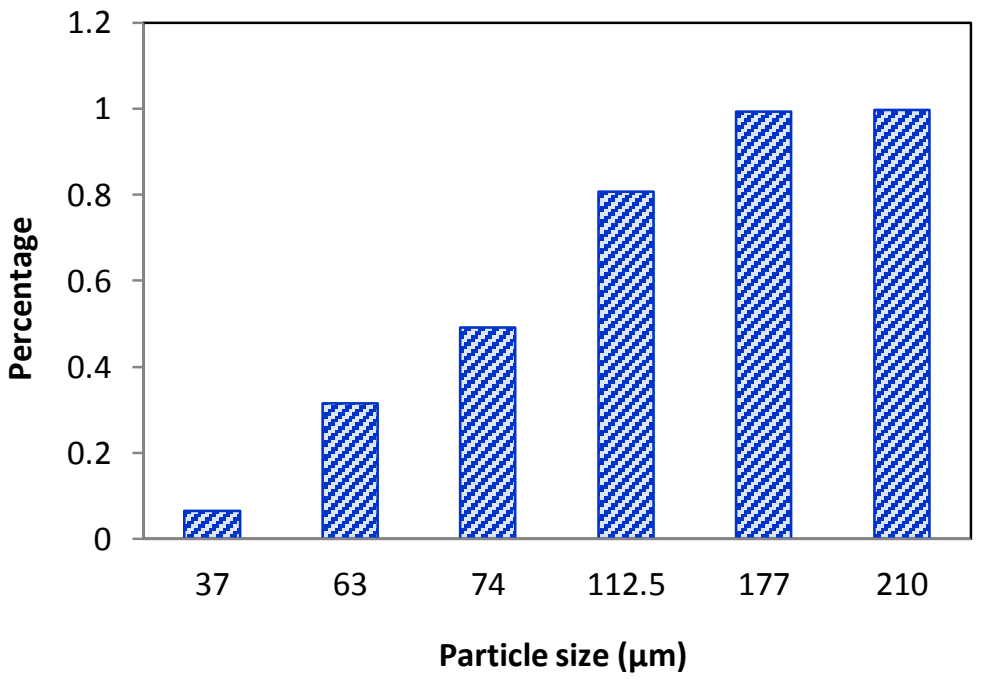

Figure 1. Particle size distribution of the used silica sands 
The mix design was selected in accordance with a commercial ECC mix design (i.e. ECC-M45), which is illustrated in Table 1. The water to cementitious material ratio $(\mathrm{w} / \mathrm{cm})$ was 0.256 .

Table 1. The used mix design

\begin{tabular}{ccccccc}
\hline Ingredients & Cement & Fly ash & sand & water & Superplasticizer & Fibers (vol\%) \\
\hline Content & 1.0 & 1.2 & 0.8 & 0.56 & 0.012 & 2 \\
\hline
\end{tabular}

Polypropylene and carbon fibers, which are illustrated in Figure 2. and their hybrid were used as reinforcement in the ECC mix designs. Table 2. shows the properties of the fibers.
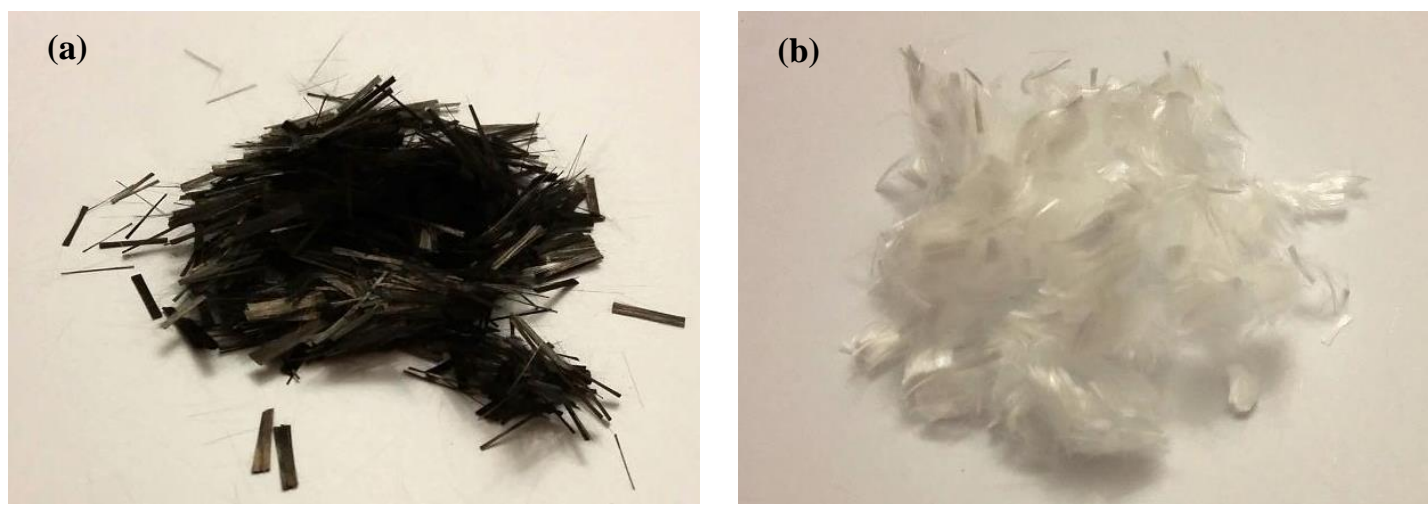

Figure 2. The used chopped fibers: (a) carbon fibers and (b) polypropylene fibers

Table 2: Properties of the used fibers

\begin{tabular}{ccccccc}
\hline Fibers & $\begin{array}{c}\text { Strength } \\
(\mathbf{M P a})\end{array}$ & $\begin{array}{c}\text { Elongation } \\
(\boldsymbol{\%})\end{array}$ & $\begin{array}{c}\text { Elastic modulus } \\
(\mathbf{G P a})\end{array}$ & $\begin{array}{c}\text { Density } \\
\left(\mathbf{g} / \mathbf{c m}^{3}\right)\end{array}$ & $\begin{array}{c}\text { diameter } \\
(\boldsymbol{\mu m})\end{array}$ & $\begin{array}{c}\text { Length } \\
(\mathbf{m m})\end{array}$ \\
\hline Polypropylene & 350 & 80 & 3 & 0.9 & 22 & 6 \\
Carbon & 2500 & 3 & 75 & 1.76 & 7 & 8 \\
\hline
\end{tabular}

\subsection{Sample Preparation}

Flexural test samples were made with dimensions of $230 \times 100 \times 9 \mathrm{~mm}$. 5 specimens were prepared for each sample to confirm the repeatability of the test results.

The hybrid of the carbon to polypropylene fibers (C:PP ratio) was performed at proportions of 100:0, 25:75, 50:50, 75:25 and 0:100. The fibers were used at 2 vol\% in the mix design. The control sample (without fiber) was also prepared.

The samples were cured in a water bath for 28 days and then removed and a four-point bending test was carried out on them.

\subsection{Four-Point Bending Test}

A four-point bending test was carried out on all the samples according to the ASTM C78 standard test method [25]. The STM-150 universal test machine with a $2000 \mathrm{~kg}$.f load cell was used. The loading rate was $1 \mathrm{~mm} / \mathrm{min}$. Figure 3 . shows the setup of the four-point bending test.

Table 1. Distance between suburbans and plants

\begin{tabular}{|c|c|c|c|c|c|c|c|c|}
\hline & & \multicolumn{7}{|c|}{ Suburbans } \\
\hline & & 1 & 2 & 3 & 4 & 5 & 6 & 7 \\
\hline \multirow{4}{*}{$\begin{array}{c}\text { Concrete } \\
\text { Batch Plants }\end{array}$} & 1 & 15 & 11 & 10 & 10 & 7.5 & 6.5 & 5 \\
\hline & 2 & 20 & 16 & 13 & 13.5 & 11.5 & 8.5 & 5 \\
\hline & 3 & 8.5 & 5 & 1.5 & 6.5 & 3.5 & 7.5 & 8 \\
\hline & 4 & 12.5 & 8 & 12.5 & 6.5 & 8 & 13.5 & 12 \\
\hline
\end{tabular}

\subsection{Parameters Definition and Calculating Method}

The flexural strength and toughness of the samples at first crack point and post crack region were calculated. First crack is defined as the point at which the curve becomes nonlinear. Flexural toughness is defined as the surface area 
under the load-deflection curve up to a definite deflection point. The deflection at the first crack point (i.e. d), $3 \mathrm{~d}$ and $5.5 \mathrm{~d}$ were determined according to the standard. The flexural toughness values (i.e. $\mathrm{T}_{\mathrm{d}}, \mathrm{T}_{3 \mathrm{~d}}$ and $\mathrm{T}_{5.5 \mathrm{~d}}$ ) were calculated using the surface area under the load-deflection curves of the samples up to the determined deflection (i.e. $d$, $3 \mathrm{~d}$ and $5.5 \mathrm{~d}$, respectively) [26]. The flexural toughness was also calculated at the deflection of $10 \mathrm{~mm}$ (i.e. $\mathrm{T}_{\mathrm{m}}$ ) due to the high ductility of the samples.

Toughness indices (I5, I10 and $\mathrm{I}_{\mathrm{m}}$ ) which represent the composite behaviour up to a definite deflection were also calculated as follows [26]:

$$
\begin{aligned}
& \mathrm{I}_{5}=\mathrm{T}_{3 \mathrm{~d}} / \mathrm{T}_{\mathrm{d}} \\
& \mathrm{I}_{10}=\mathrm{T}_{5.5 \mathrm{~d}} / \mathrm{T}_{\mathrm{d}} \\
& \mathrm{I}_{\mathrm{m}}=\mathrm{T}_{\mathrm{m}} / \mathrm{T}_{\mathrm{d}}
\end{aligned}
$$

The residual strength factor $(\mathrm{R} 5,10)$ is the other parameter which represents the average strength retained after the first crack as a percentage of the first crack strength between $3 \mathrm{~d}$ and $5.5 \mathrm{~d}$ deflections (see Equation 4 ). The value of this factor is 100 for perfectly plastic material and 0 for plain concrete. The values of less than 50 indicate the inferior performance and the values between 50 and 100 indicate that the behaviour of the material has been close to the plastic materials behaviour [26].

$$
\mathrm{R}_{5,10}=20\left(\mathrm{I}_{10}-\mathrm{I}_{5}\right)
$$

\section{Results and Discussions}

As illustrated in Figure 4, the control sample (without fiber) is brittle and its flexural load is about $216 \mathrm{~N}$. Generally, the addition of fibers improves the flexural behaviour of the composite. The sample with 2 vol\% carbon fibers shows brittle behaviour as well. However, the flexural load and deflection have been increased by $260 \%$ and $330 \%$, respectively.

The sample reinforced by 2 vol\% polypropylene fibers shows tension softening behaviour. This means that the fibers bridge on the crack after the first crack creation and resist crack opening. By increasing the applied load, the cracks propagate and the sample shows plastic behaviour. In this region, the applied load leads to fibers elongation and thus energy dissipation. Although the first peak of this sample is similar to the control sample, its deflection is 48 times more than the deflection of the control sample. This leads to a significant increase in its flexural toughness.

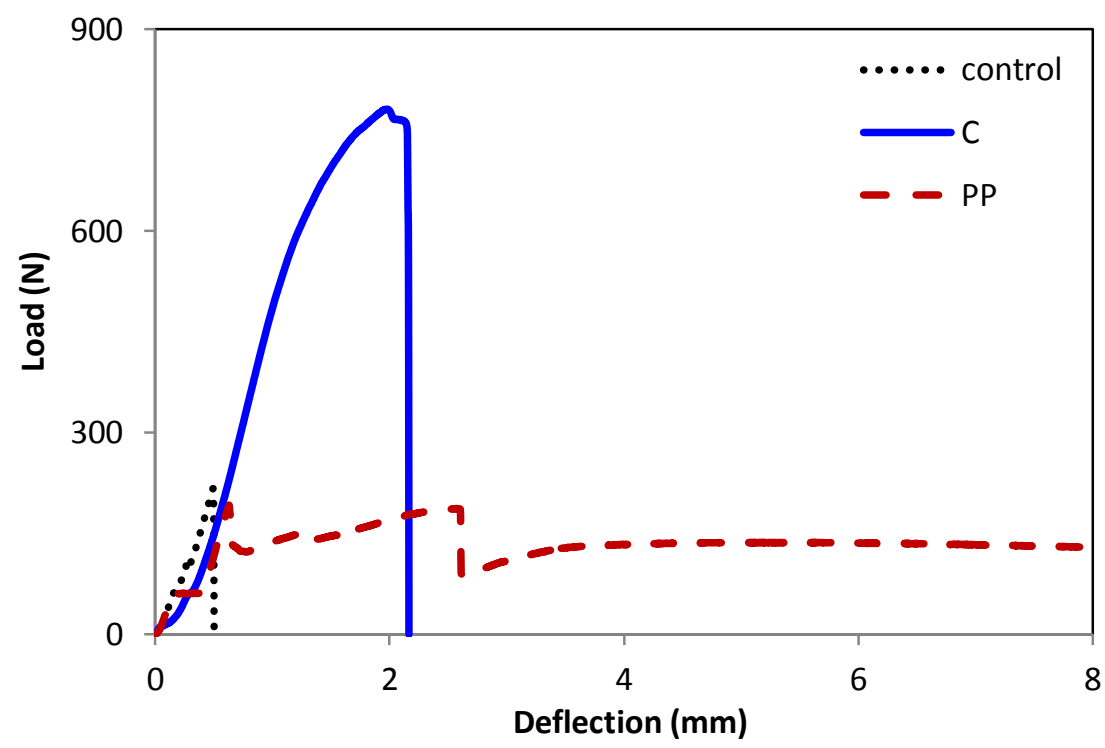

Figure 4. Load-deflection curve of the reinforced sample with 2 vol\% carbon and polypropylene fibers

On the basis of the results, it seems that hybridization of the carbon and polypropylene fibers could lead to simultaneous improvement in the flexural load and the toughness. If this assumption is true, the second step would be finding the optimum hybridization ratio.

Figure 5. shows the flexural load-deflection curves of all the samples. The hybrid samples show high deflection and tension softening behaviour similar to the polypropylene fiber reinforced concrete, while the flexural load has 
been increased.

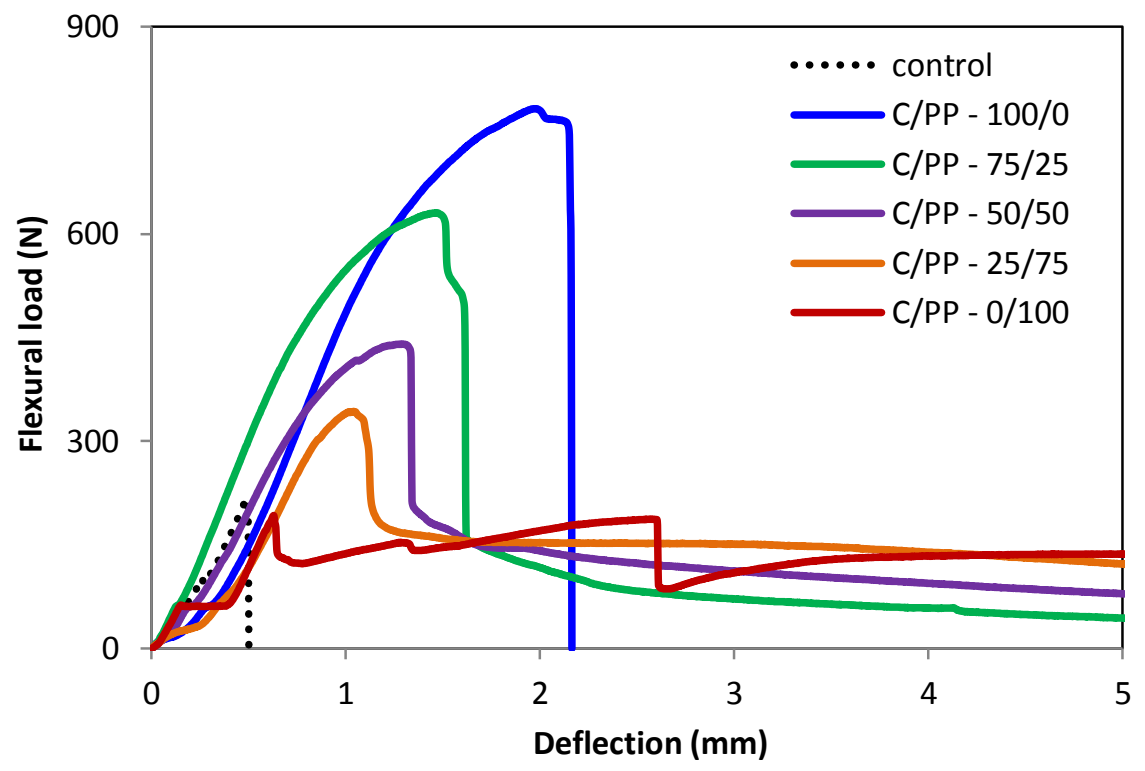

Figure 5. Flexural load-deflection curves

It should be mentioned that the flexural loads of the hybrid samples have been increased from 58\% to $190 \%$ in comparison to the control sample (see Figure 6). This is related to the high strength/modulus carbon fibers. The flexural load of the composites decreases with a decrease in the carbon fibers and its replacement by polypropylene fibers.

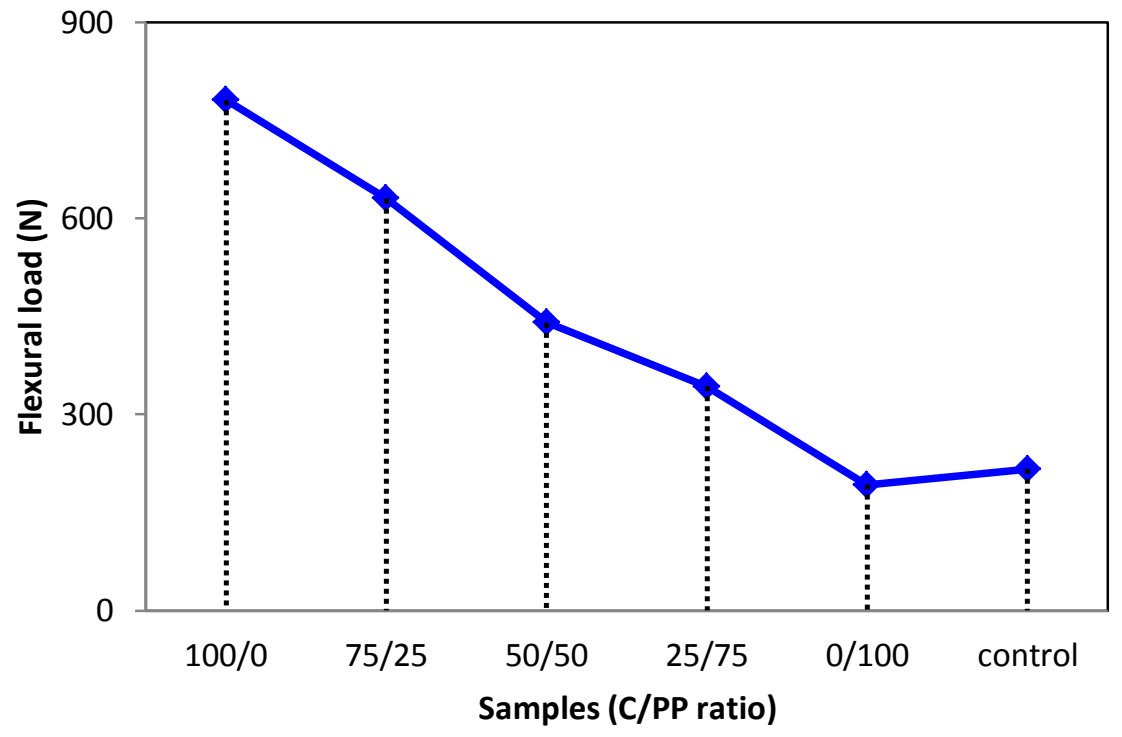

Figure 6. Flexural load of the samples

Figure 7. shows the crack patterns of the samples. It is obvious that one micro crack has been created and propagated along the carbon fiber reinforced sample. However, several cracks have been created along the hybrid samples and the specimen containing polypropylene fibers. It is seen that these sample have not been fractured yet. 

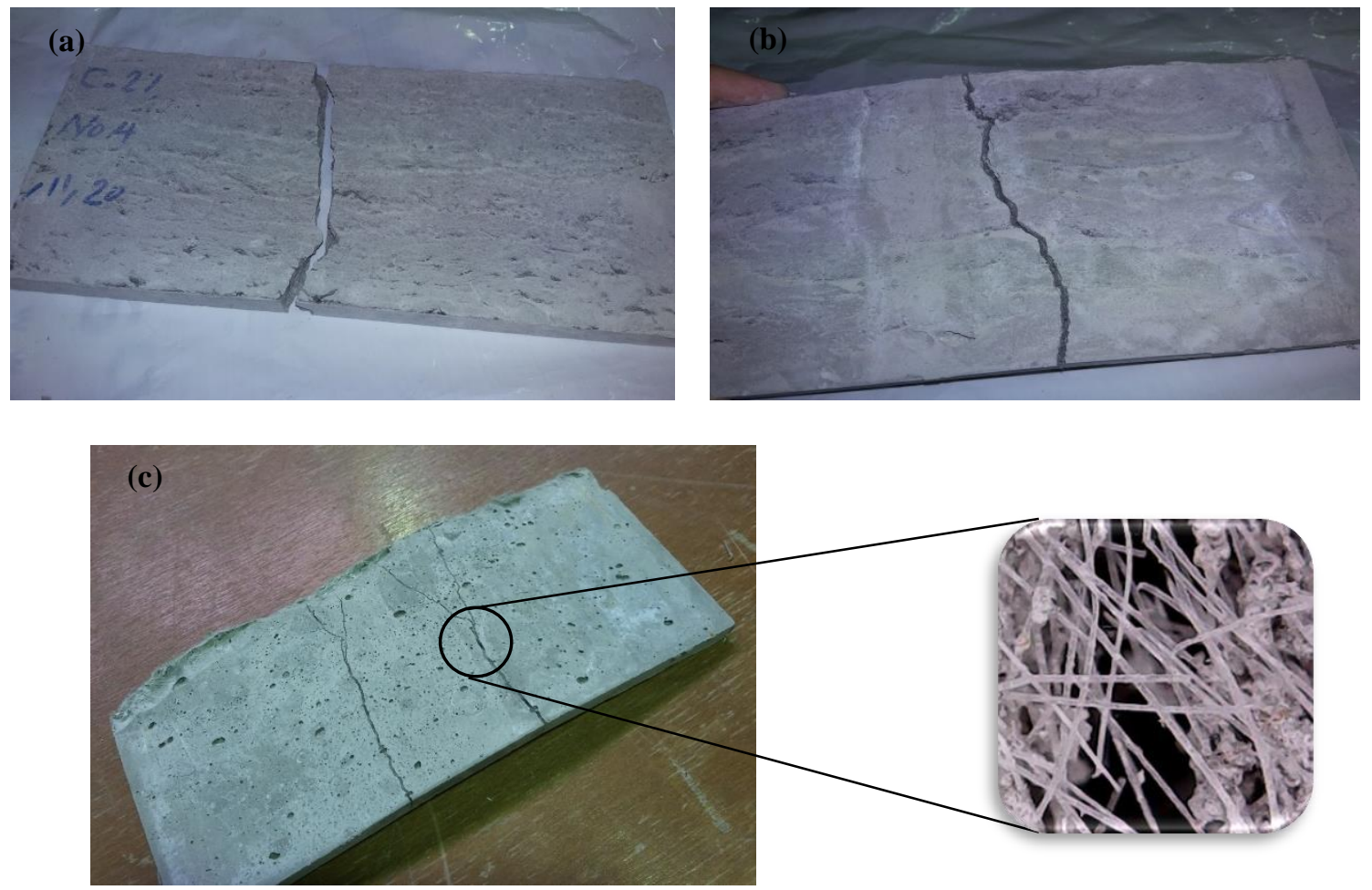

Figure 7. Fibers bridging on the crack and the yield configuration of the samples containing (a) carbon fibers (b) hybrid fibers and (c) polypropylene fibers

Table 3. represents the parameters which are calculated according to Equations 1-4.

Table 3. Results of bending test

\begin{tabular}{cccccccccc}
\hline $\begin{array}{c}\text { Sample } \\
(\mathbf{C : P P})\end{array}$ & $\begin{array}{c}\text { Flexural load } \\
(\mathbf{N})\end{array}$ & $\begin{array}{c}\mathbf{T}_{\mathbf{d}} \\
(\mathbf{N} . \mathbf{m m})\end{array}$ & $\begin{array}{c}\mathbf{T}_{\mathbf{3 d}} \\
(\mathbf{N} . \mathbf{m m})\end{array}$ & $\begin{array}{c}\mathbf{T}_{5.5 \mathbf{d}} \\
(\mathbf{N} . \mathbf{m m})\end{array}$ & $\begin{array}{c}\mathbf{T}_{\mathbf{m}} \\
(\mathbf{N} . \mathbf{m m})\end{array}$ & $\mathbf{I}_{\mathbf{5}}$ & $\mathbf{I}_{\mathbf{1 0}}$ & $\mathbf{I}_{\mathbf{m}}$ & $\mathbf{R}_{\mathbf{5}, \mathbf{1 0}}$ \\
\hline Control & 216.8 & - & - & - & 48.7 & - & - & - & - \\
$100: 0$ & 780.9 & - & - & - & 984.4 & - & - & - & - \\
$75: 25$ & 630.3 & 572.5 & 877.5 & 1010.6 & 1056.0 & 1.5 & 1.7 & 1.8 & 4.4 \\
$50: 50$ & 440.5 & 319.6 & 662.7 & 902.0 & 1061.5 & 2.1 & 2.8 & 3.3 & 14.6 \\
$25: 75$ & 342.9 & 158.7 & 497.1 & 837.8 & 1176.1 & 3.1 & 5.3 & 7.4 & 42.9 \\
$0: 100$ & 192.3 & 48.3 & 230.1 & 451.6 & 1311.1 & 4.8 & 9.3 & 27.2 & 91.8 \\
\hline
\end{tabular}

The flexural toughness of the carbon fiber reinforced sample has been increased 20 times (i.e. 1920\%) compared to the control sample, but this sample still shows brittle behaviour. The flexural toughness has not shown a significant difference by replacing carbon fiber with polypropylene fibers up to $50 \%$. However, it has been increased for the samples containing more than $50 \%$ polypropylene fibers. The flexural toughness of the polypropylene fibers reinforced sample has been increased $33 \%$ in comparison to the sample reinforced just by carbon fibers (see Figure 8). 


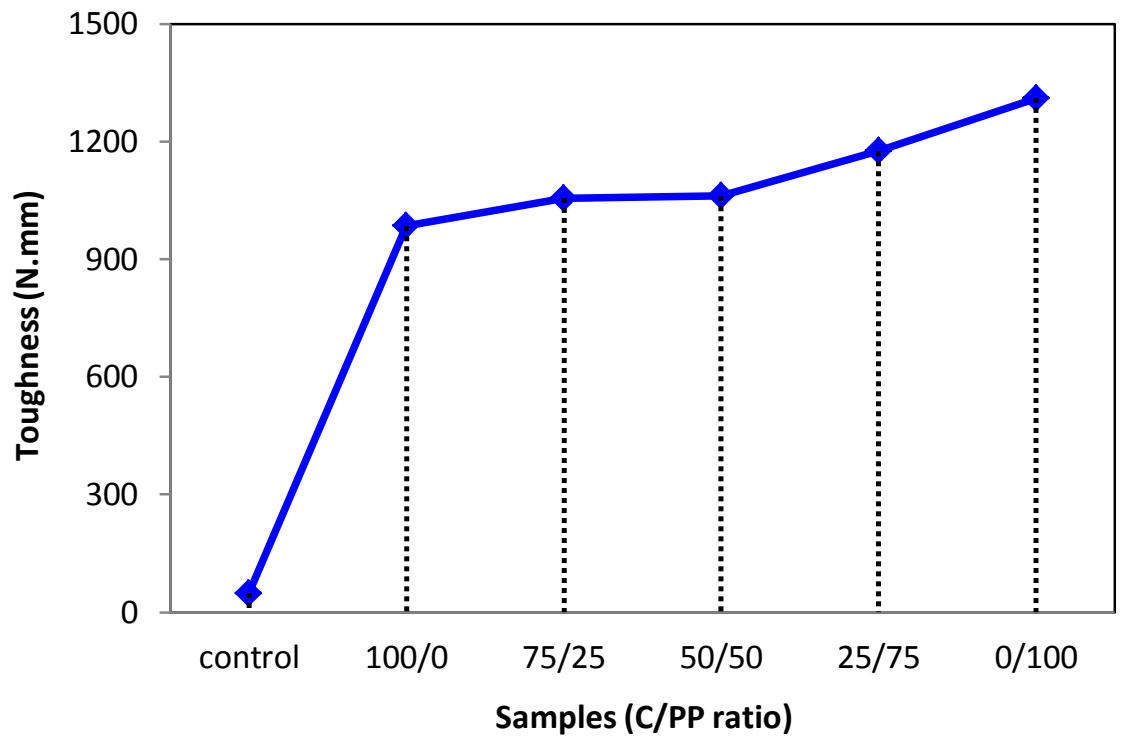

Figure 8. Flexural toughness of the samples

By an increase in the carbon fibers content, the first crack was created at higher deflections and at higher load bearing capacities. Therefore, the toughness values of the samples at the first crack point (i.e. $T_{d}$ ) have shown an inverse behaviour. This means that the $T_{d}$ and therefore the $T_{3 d}$ and $T_{5.5 d}$ have been decreased by a decrease in the carbon fibers content (see Figure 9).

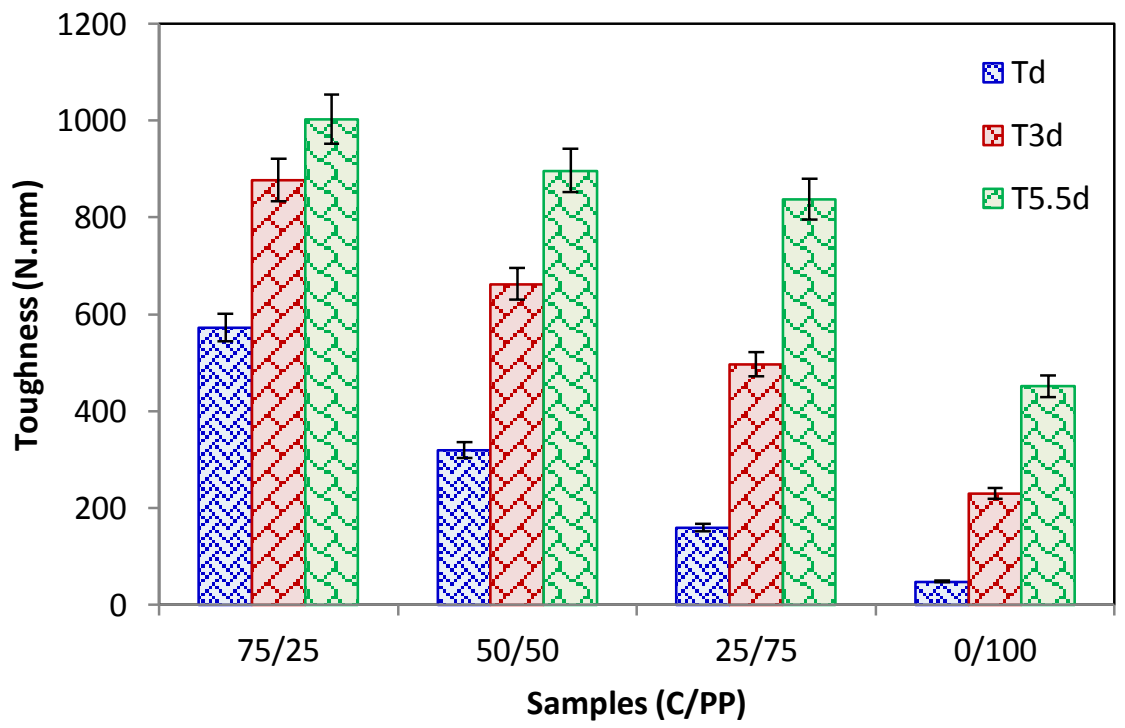

Figure 9. Flexural toughness up to the deflection of $d, 3 d$ and $5.5 d$

It should be noted that it was impossible to calculate these factors for the control and the carbon fiber reinforced sample, due to their brittle behaviour.

According to Figure 10, the toughness indices are in a direct relationship with an increase in the polypropylene fibers content. This shows that the configuration of the composite would change from brittle behaviour to tension softening behaviour. This is in a good accordance with the flexural load-deflection curves of the samples. 


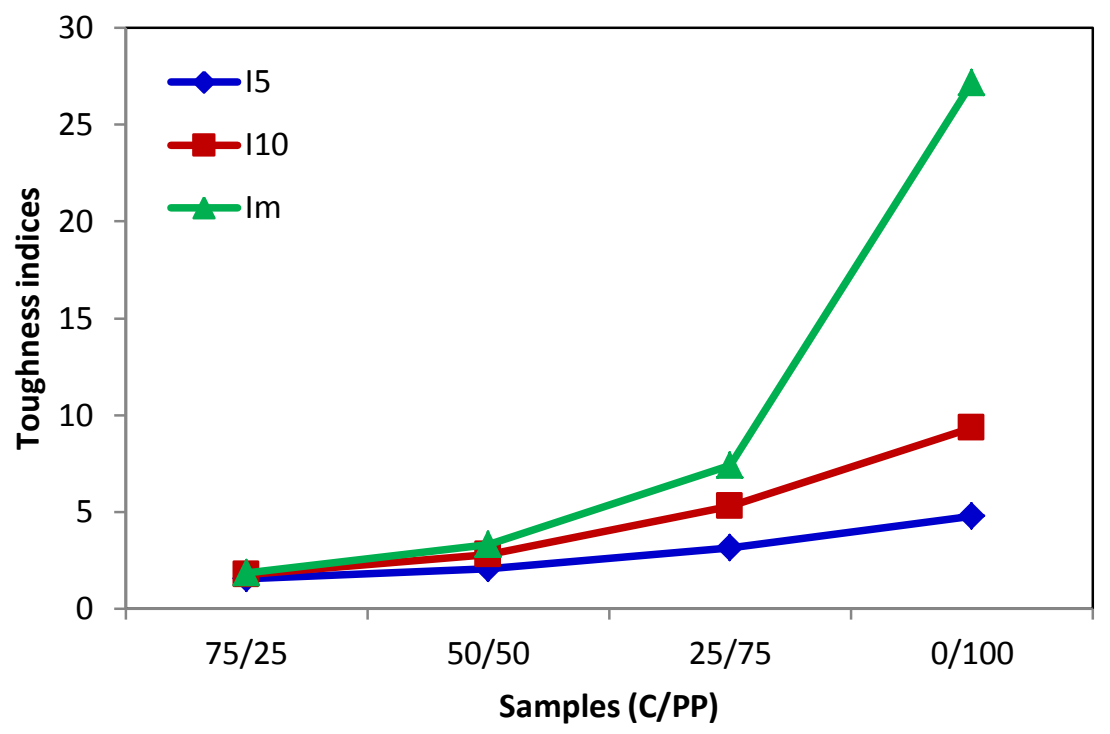

Figure 10. The toughness indices of the samples

The residual strength factor $\left(\mathrm{R}_{5,10}\right)$ is the other parameter which has been investigated in this study. As illustrated in Table 3, it can be seen that all the results are in the range of 0 to 100 . The value of $R_{5,10}$ is close to 0 for the C:PP$75: 25$ sample. This means that the behaviour of this sample is similar to the regular concrete. However, the $\mathrm{R}_{5,10}$ value of the polypropylene reinforced sample (i.e. C:PP-0:100) is near 100. This shows that the behaviour of the composite is close to the plastic materials behaviour.

Therefore, according to the results, it seems that the hybrid sample C:PP-50:50 represents a suitable load and toughness, which have been increased to $103 \%$ and $2080 \%$, respectively, compared to the control sample. In addition, the cost of this sample is much less than the carbon fiber reinforced sample.

\section{Conclusion}

In this paper, the effect of using short carbon and polypropylene fibers individually and their hybridization as reinforcement in a kind of fine aggregate concrete has been investigated. The following results were obtained:

- Using carbon fiber as reinforcement causes a considerable increment (i.e. 260\%) in flexural load of the fine aggregate concrete in comparison to the control sample (without fiber).

- Using polypropylene fiber as reinforcement causes a considerable increment (i.e. 2590\%) in flexural toughness of the fine aggregate concrete in comparison to the control sample.

- Replacing $75 \%$ of carbon fiber with polypropylene fiber in the hybrid fibers system, caused a 56\% decrease in flexural load, $20 \%$ increase in toughness, but considerable decrease in cost.

- Replacing $25 \%$ of carbon fiber with polypropylene fiber caused a considerable decrease in the cost of fiber but negligible increase in toughness and about $20 \%$ decrease in flexural load.

- Incorporating polypropylene fiber significantly improved flexural toughness and toughness indices, but even in the hybrid system, the samples still show pseudo brittle behaviour.

\section{References}

[1] Nawy, Edward G., ed. Concrete construction engineering handbook. CRC press, 2008.

[2] Hamoush, Sameer, Taher Abu-Lebdeh, and Toney Cummins. "Deflection behavior of concrete beams reinforced with PVA micro-fibers." Construction and Building Materials 24, no. 11 (2010): 2285-2293.

[3] Bentur A, Mindess S, Fibre Reinforced Cementitious Composites, Elsevier Science Publishers LTD, (1990).

[4] Sukontasukkul, Piti. "Tensile Behaviour of High Content Steel and Polypropylene Fibre Reinforced Mortar." Thammasat Int J Sci Technol 8, no. 3 (2003): 50-56.

[5] Kim, Dong joo, Antoine E. Naaman, and Sherif El-Tawil. "Comparative flexural behavior of four fiber reinforced cementitious composites." cement \& concrete composites 30, no. 10 (2008): 917-928.

[6] Jamshidi, M., and A. A. Ramezanianpour. "Laboratory and industrial investigations on hybrid of acrylic and glass short fibers as an alternative for substituting asbestos in Hatschek process." Construction and Building Materials 25, no. 1 (2011): 298-302. 
[7] Katz, Amnon, Victor C. Li, and A. Kazmer. "Bond properties of carbon fibers in cementitious matrix." Journal of materials in civil engineering 7, no. 2 (1995): 125-128.

[8] Song, P. S., S. Hwang, and B. C. Sheu. "Strength properties of nylon-and polypropylene-fiber-reinforced concretes." Cement and Concrete Research 35, no. 8 (2005): 1546-1550.

[9] Dawood, Eethar Thanon, and Mahyuddin Ramli. "Contribution of hybrid fibers on the properties of high strength concrete having high workability." Procedia Engineering 14 (2011): 814-820.

[10] Wen, Sihai, and D. D. L. Chung. "A comparative study of steel-and carbon-fibre cement as piezoresistive strain sensors." Advances in cement research 15, no. 3 (2003): 119-128.

[11] Aziz OQ, Taha BO, Flexural Behavior of High Strength Concrete (HSC) Beams Reinforced with Carbon Reinforced Polymer (CFRP) Rebars with and without Chopped Carbon Fiber (CCF), International Journal of Scientific Research in Knowledge (IJSRK), 1 (2013): 123-139.

[12] Park, Seung Bum, and Burtrand I. Lee. "Mechanical properties of carbon-fiber-reinforced polymer-impregnated cement composites." Cement and Concrete Composites 15, no. 3 (1993): 153-163.

[13] Toutanji, Houssam A., Tahar El-Korchi, and R. Nathan Katz. "Strength and reliability of carbon-fiber-reinforced cement composites." Cement and concrete composites 16, no. 1 (1994): 15-21.

[14] Kinayekar SM, Gundakalle VD, Kulkarni K, The Effect of Addition of Carbon Fibers on Mechanical Properties of High Strength Concrete, International Journal of Innovative Research in Science, Engineering and Technology, 3 (2014): 8777-8784.

[15] Chung, D. D. L. "Cement reinforced with short carbon fibers: a multifunctional material." Composites Part B: Engineering 31, no. 6 (2000): 511-526.

[16] Bagherzadeh, Roohollah, Hamid Reza Pakravan, Abdol-Hossein Sadeghi, Masoud Latifi, and Ali Akbar Merati. "An investigation on adding polypropylene fibers to reinforce lightweight cement composites (LWC)." journal of Engineered Fibers and Fabrics 7, no. 4 (2012): 13-21.

[17] Yao, Wu, Jie Li, and Keru Wu. "Mechanical properties of hybrid fiber-reinforced concrete at low fiber volume fraction." Cement and concrete research 33, no. 1 (2003): 27-30.

[18] Song, Weimin, and Jian Yin. "Hybrid Effect Evaluation of Steel Fiber and Carbon Fiber on the Performance of the Fiber Reinforced Concrete." Materials 9, no. 8 (2016): 704.

[19] Singh, S. P., A. P. Singh, and V. Bajaj. "Strength and flexural toughness of concrete reinforced with steel-polypropylene hybrid fibres." Asian Journal of Civil Engineering (Building and Housing) 11, no. 4 (2010): 494-507.

[20] Sorelli, Luca, Nemkumar Banthia, Vivek Bindiganavile, and Giovanni Plizzari. "Static and dynamic responses of hybrid fiber reinforced concrete." In International Conference on Advances in Concrete and Structures, edited by Ying-shu Yuan, Surendra P. Shah, and Heng-lin Lü, pp. 1023-1030. RILEM Publications SARL, 2003.

[21] Selina Ruby G, Geethanjali C, Varghese J, Muthu Priya P, Influence of Hybrid Fiber on Reinforced Concrete, International Journal of Advanced Structures and Geotechnical Engineering, 3 (2014): 40-43.

[22] Naaman, A. E., and H. W. Reinhardt. "Setting the stage: Toward performance based classification of FRC composites." In High Performance Fiber Reinforced Cement Composites, vol. 4, pp. 1-4. 2003.

[23] Li, Victor C. "Advances in ECC research." Special Publication 206 (2002): 373-400.

[24] Li VC, Engineered cementitious composites (ECC) - Material, structure, and durability performance. In: Nawy E (ed.), Concrete Construction Engineering Handbook, Boca Raton: CRC Press, Chapter 24, (2008): 1-40.

[25] ASTM C 78. Standard test method for flexural strength of concrete (using simple beam with third-point loading). American Society for Testing Materials.

[26] ASTM C 1018-97, Standard test method for flexural toughness and first-crack strength of fiber-reinforced concrete (using beam with third-point loading), American Society for Testing Materials, 2006. 